\title{
Bone Age at Onset of Pubertal Growth Spurt and Final Height in Normal Children
}

\author{
Mari Satoh and Toshiaki Tanaka \\ Endocrine Research Laboratory, National Children's Medical Research Center, Tokyo, Japan
}

\begin{abstract}
The purpose of this study was to examine the influence of the variation in bone age at the onset of the pubertal growth spurt (PGS) on pubertal height gain and on final height. The subjects were 26 boys and 28 girls who had been treated at the Department of Orthodontics, School of Dentistry, Tohoku University, and had reached their final heights. Each child had longitudinal growth record and several hand and wrist X-ray films.

A significant positive correlation between the bone age and height at the onset of PGS was recognized in boys $(\mathrm{r}=0.734, \mathrm{P}<0.01, \mathrm{n}=26)$ and girls $(\mathrm{r}=0.655, \mathrm{P}<0.01, \mathrm{n}=28)$. A significant negative correlation between the bone age at the onset of PGS and the pubertal height gain was recognized in boys $(\mathrm{r}=-0.732, \mathrm{P}<0.01)$ and girls $(\mathrm{r}=-0.775, \mathrm{P}<0.01)$. However, there was no significant correlation between final height and bone age at the onset of PGS.

We found that the rate of bone maturation during puberty negatively correlated with the bone age at the onset of PGS and although bone age at the onset of PGS was distributed over a wide range, bone age at PHV was concentrated around 13 years in boys and 11 years in girls.
\end{abstract}

Key words: bone age, pubertal growth spurt, peak height velocity, pubertal height gain, final height

\section{Introduction}

Growth during the pubertal period has an important influence on final height. Tanaka et al. $(1,2)$ report that final height is significantly related to height at the onset of the PGS and that the later pubertal maturation occurs, the greater the final height achieved for a given height before puberty. Many factors, such as

Received: April 11, 1995

Accepted: May 31, 1995

Correspondence: Dr. Mari Satoh, Endocrine Research Laboratory, National Children's Medical Research Center, 3-35-31, Taishido,

Setagaya-ku, Tokyo 154 Japan growth hormone (GH), sex steroid hormones, nutrition, genetics, etc., have an influence on pubertal growth, as does bone age. In this study, we studied the influence of the variation in bone age at the onset of PGS on pubertal height gain and on final height.

\section{Subjects and Methods}

The subjects were 26 boys and 28 girls who had been treated for mandibular prognathism at the Department of Orthodontics, School of Dentistry, Tohoku University, and had reached their final heights. They had longitudinal growth 
records and several hand and wrist X-ray films. Individual growth curves, growth velocity curves, and bone age/chronological age curves were drawn by a smoothing cubic spline function using an NEC-PC98 personal computer with the software program "Spline Smoothing Analysis." Chronological age, bone age, and height both at the onset of PGS and at peak height velocity (PHV) were calculated from these curves. We defined the greatest height after the growth velocity slowed to less than 1.0 $\mathrm{cm} /$ year as the final height. The TannerWhitehouse 2 RUS scoring system standardized for Japanese children (3) was used for bone age estimation. Height standard deviation (SD) score was calculated using the national data provided in 1980 by the Ministry of Education and Welfare of Japan. For statistical evaluation, student's t-test and Pearson's correlation coefficients were used.

\section{Results}

Table 1 shows the clinical characteristics of the subjects. We compared the growth of our subjects to the Japanese standard reported by Suwa et al. (4)(Table 2). In boys, the mean final height of our subjects was significantly greater than the Japanese standard, and the mean chronological age at $\mathrm{PHV}$ of our subjects was significantly younger than the Japanese standard. In girls, the mean final height was significantly greater than the Japanese standard. However, there was no significant difference in the mean chronological age at PHV between our subjects and the Japanese standard.

The influence of the variation in bone age at the onset of PGS on the final height was inves-
Table 1 Clinical data.

\begin{tabular}{|c|c|c|}
\hline & Boys $(n=26)$ & Girls $(n=28)$ \\
\hline Height at 7 years old $(\mathrm{cm})$ & $119.8 \pm 4.2$ & $118.8 \pm 4.2$ \\
\hline \multicolumn{2}{|l|}{ At onset of PGS } & $0.15 \pm 0.82$ \\
\hline Chronological age (years) & $9.72 \pm 1.05$ & $8.71 \pm 1.01$ \\
\hline Bone age (years) & $9.99 \pm 1.61$ & $8.89 \pm 1.26$ \\
\hline Height $(\mathrm{cm})$ & $134.9 \pm 5.5$ & $128.4 \pm 6.7$ \\
\hline $\begin{array}{l}\text { Height SDS for } \\
\text { chronological age (SD) }\end{array}$ & $0.26 \pm 0.84$ & $0.10 \pm 0.82$ \\
\hline \multicolumn{3}{|l|}{ At PHV } \\
\hline Chronological age (years) & $12.52 \pm 1.06$ & $11.04 \pm 0.79$ \\
\hline Bone age (years) & $12.86 \pm 0.61$ & $11.04 \pm 0.68$ \\
\hline Height $(\mathrm{cm})$ & $153.4 \pm 4.8$ & $143.0 \pm 5.8$ \\
\hline $\begin{array}{l}\text { Height SDS for } \\
\text { chronological age (SD) }\end{array}$ & $0.49 \pm 1.03$ & $0.14 \pm 0.83$ \\
\hline Pubertal height gain $(\mathrm{cm})$ & $37.3 \pm 4.7$ & $32.6 \pm 5.8$ \\
\hline $\begin{array}{l}\text { Duration between onset } \\
\text { of PGS and PHV (years) }\end{array}$ & $2.79 \pm 0.76$ & $2.33 \pm 0.61$ \\
\hline Final height $(\mathrm{cm})$ & $172.3 \pm 4.5$ & $160.9 \pm 6.3$ \\
\hline Final height SDS (SD) & $0.51 \pm 0.84$ & $0.79 \pm 1.23$ \\
\hline
\end{tabular}

$($ mean $\pm S D)$

Table 2 Comparison of growth between our subjects and Japanese standard (Boys and Girls).

\begin{tabular}{|c|c|c|c|}
\hline Boys & $\begin{array}{l}\text { Our subjects } \\
\qquad(n=26)\end{array}$ & $\begin{array}{l}\text { Japanese standard } \\
\qquad(n=439)\end{array}$ & p value \\
\hline Height at 7 years old $(\mathrm{cm})$ & $119.8 \pm 4.2$ & $118.4 \pm 4.5$ & NS \\
\hline Final height $(\mathrm{cm})$ & $172.3 \pm 4.5$ & $169.6 \pm 5.7$ & $<0.01$ \\
\hline \multirow[t]{3}{*}{ Chronological age at PHV (years) } & $12.52 \pm 1.06$ & $13.05 \pm 0.94$ & $<0.05$ \\
\hline & \multicolumn{3}{|r|}{ (mean $\pm S D)$} \\
\hline & $\begin{array}{l}\text { Our subjects } \\
\qquad(n=28)\end{array}$ & $\begin{array}{l}\text { Japanese standard } \\
\qquad(n=483)\end{array}$ & p value \\
\hline Height at 7 years old $(\mathrm{cm})$ & $118.8 \pm 4.2$ & $117.0 \pm 5.1$ & $<0.05$ \\
\hline Final height $(\mathrm{cm})$ & $160.9 \pm 6.3$ & $157.0 \pm 5.2$ & $<0.01$ \\
\hline Chronological age at PHV (years) & $11.04 \pm 0.79$ & $11.05 \pm 1.05$ & NS \\
\hline
\end{tabular}




\section{BA and Growth during Puberty}

tigated. Fig. 1 shows the relationships between bone age at the onset of PGS and the final height, height at the onset of PGS, and pubertal height gain. A significant positive linear correlation was recognized between height and bone age at the onset of PGS in boys $(r=0.734, \mathrm{P}<0.01)$ and girls $(\mathrm{r}=0.655, \mathrm{P}<0.01)$. A significant negative linear correlation was recognized between pubertal height gain and bone age at the onset of PGS in boys $(r=-0.732, P<0.01)$ and girls $(r=-0.775, P<0.01)$. In contrast, final height was

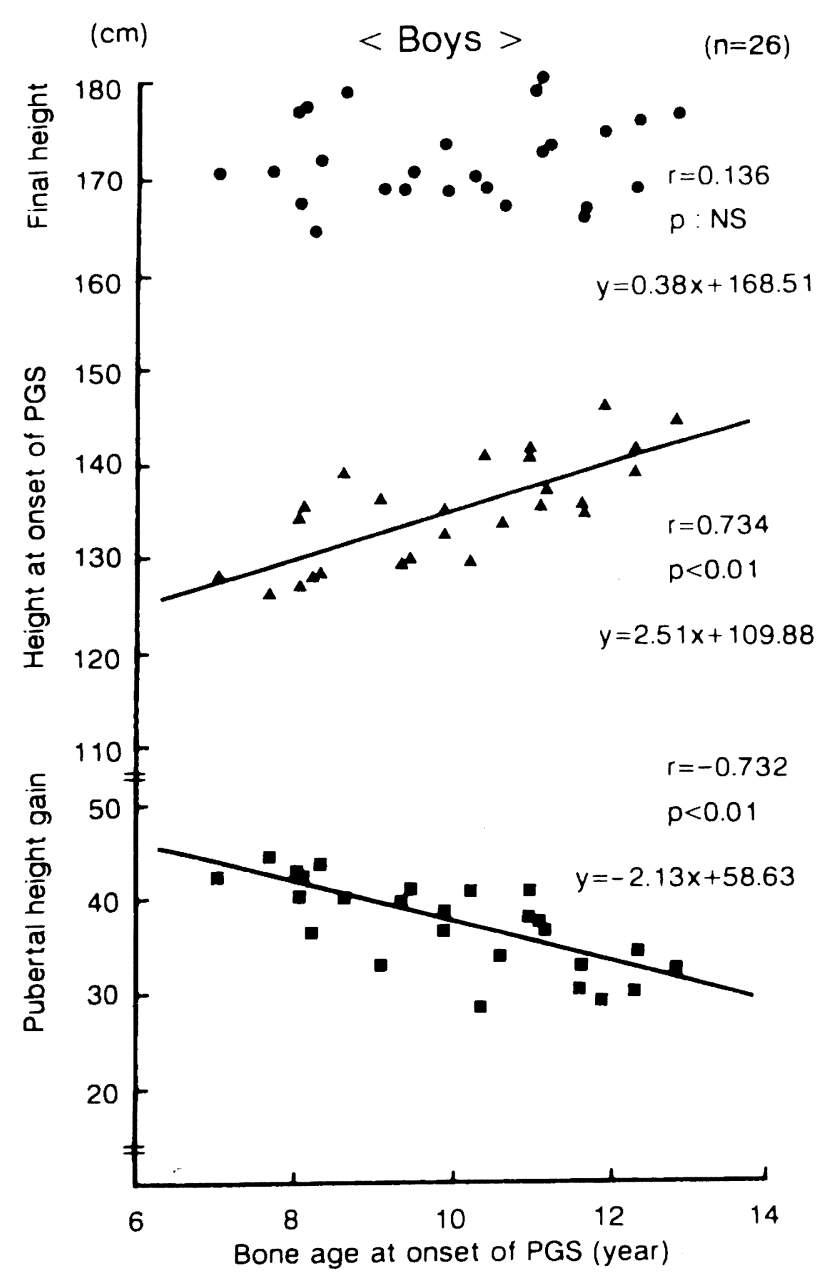

1-a not significantly related to bone age at the onset of PGS.

The rate of bone maturation during puberty was studied (Fig. 2 ). The $\Delta$ bone age/ $\Delta$ chronological age ratios were calculated at 1 year, 2 years, and 3 years after the onset of PGS. There was a significant negative linear correlation between the $\Delta$ bone age/ $\Delta$ chronological age ratio and the bone age at the onset of PGS in all cases in boys and girls.

Fig. 3 shows the differences between the

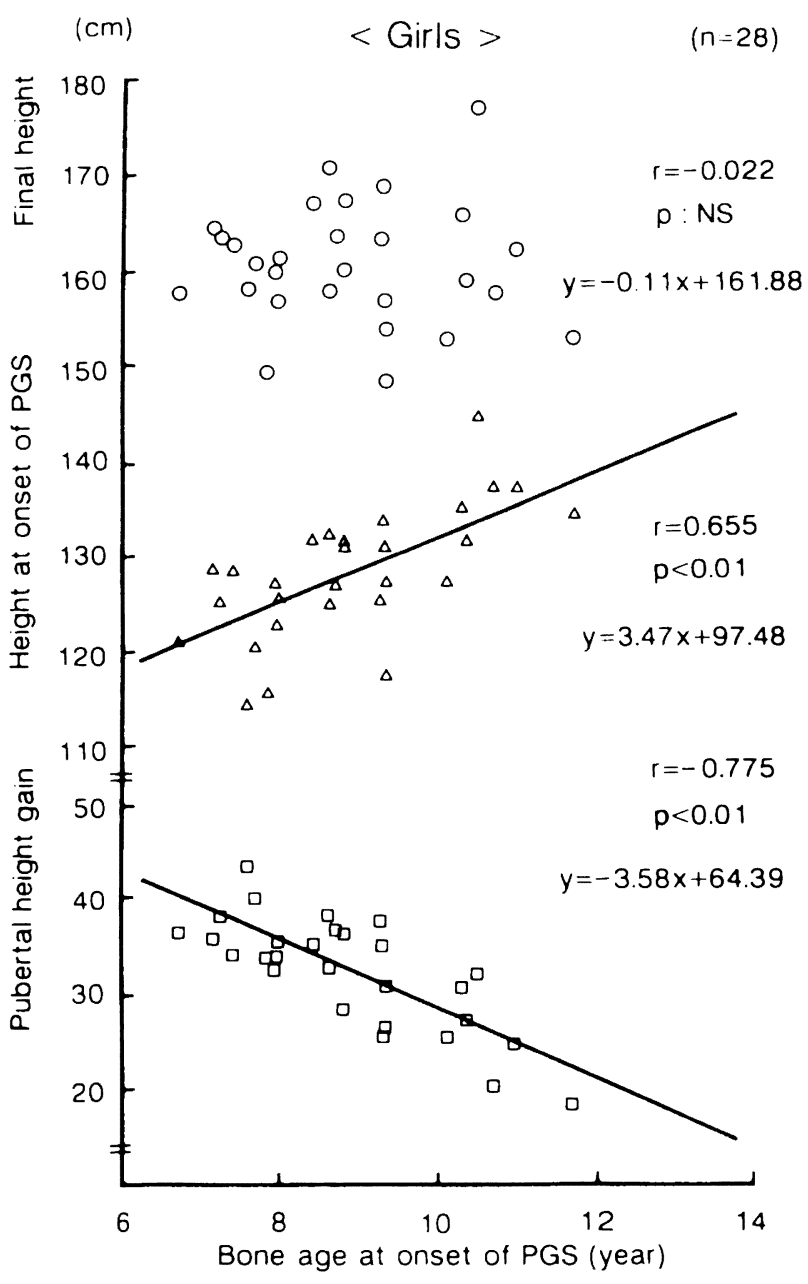

1-b

Fig. 1 Correlation between bone age at the onset of PGS and final height, height at the onset of PGS, and pubertal height gain in boys (1-a) and girls (1-b). 
changes in bone age and chronological age at the onset of PGS and at PHV. SD values in chronological age were equivalent to 1 year at the onset of PGS and at PHV. On the other hand, the SD in bone age changed from 1.61 at the onset of PGS to 0.61 at PHV in boys and from 1.26 at the onset of PGS to 0.68 at PHV in girls. Hence, although the bone age at the onset of PGS was distributed over a wide range, the bone age at PHV was concentrated around 13 years in boys and 11 years in girls.

Growth velocities were calculated from individual growth velocity curves, and were plotted against chronological ages (Fig. 4-a, b)

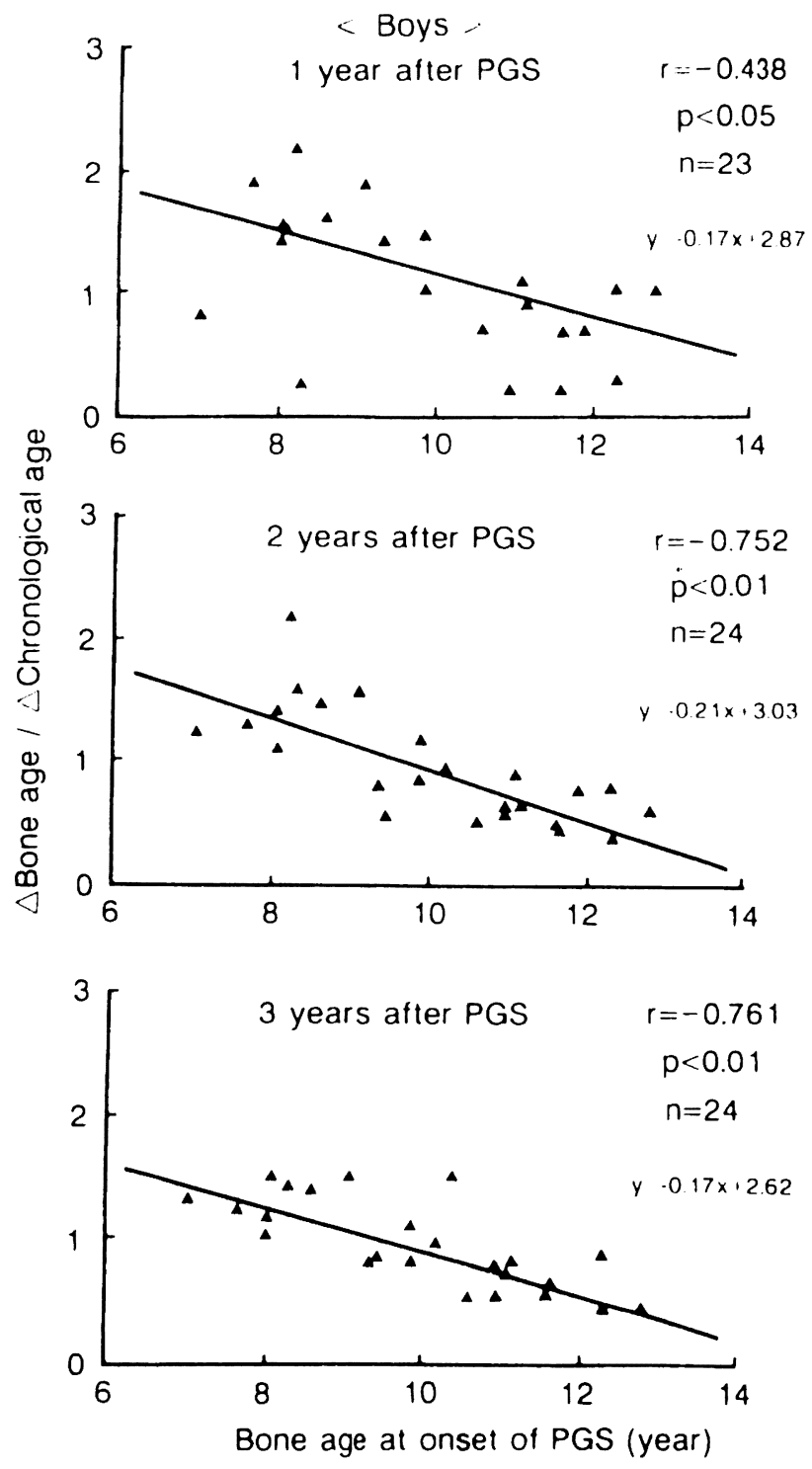

2-a
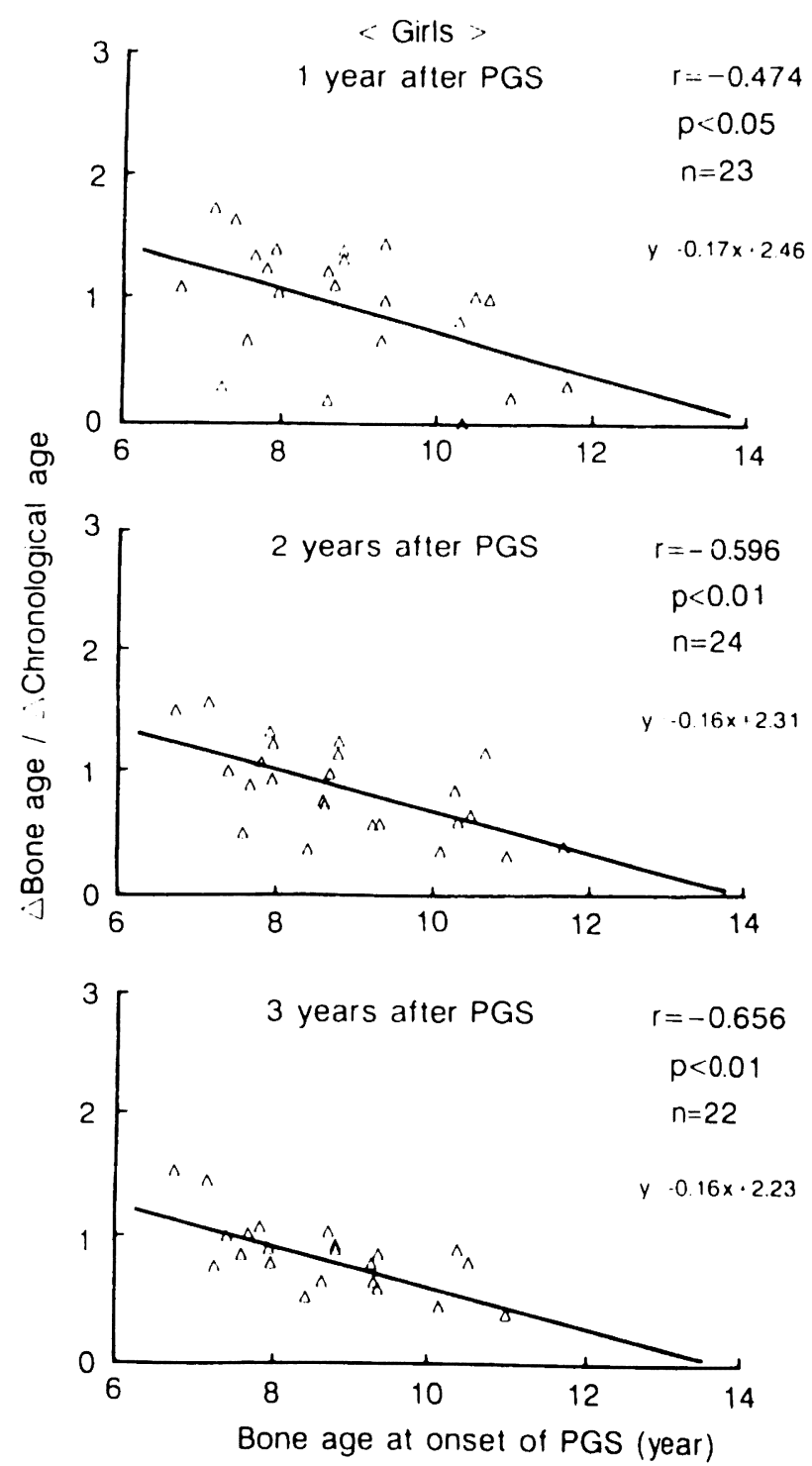

$\mathbf{2 - b}$

Fig. 2 Correlation between bone age at the onset of PGS and $\Delta$ bone age / $\Delta$ chronological age ratios at 1 year, 2 years, and 3 years after the onset of PGS in boys (2-a) and girls (2-b). 


\section{BA and Growth during Puberty}

and bone ages (Fig. 4-c, d). Growth velocities plotted against chronological ages were widely scattered because the study included both early and late maturers. However, growth velocities plotted against bone ages were distributed along the standard height velocity curve.

The factors related to the increase in height SD score were studied. The difference between the final height SD score and the height SD score at 7 years was defined as the $\Delta$ height SD score ( $\Delta$ HSDS). Table 3 shows the correlation coefficients between $\Delta$ HSDS and several factors. In boys, $\Delta$ HSDS positively correlated to chronological age at the onset of PGS, chronological age at $\mathrm{PHV}$, and the difference between chronological age and bone age at PHV. In girls,

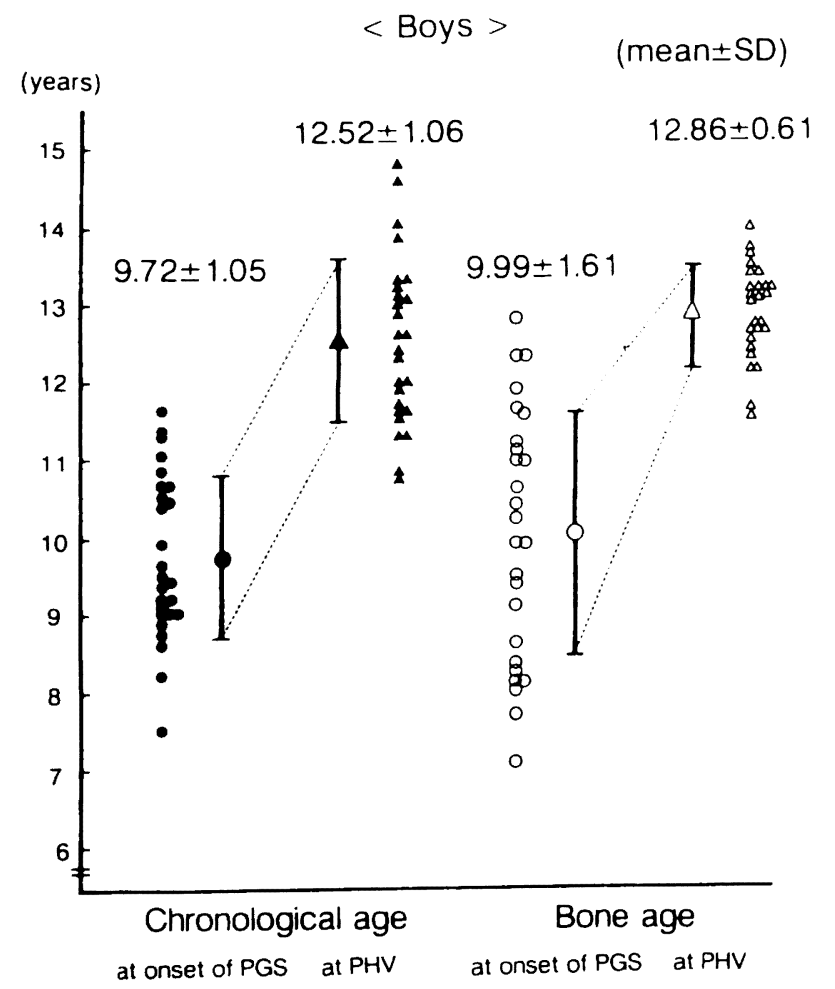

3-a
$\Delta$ HSDS positively correlated to the height SD score for chronological age at the onset of PGS and at PHV, chronological age at PHV, and the difference between chronological age and bone age at PHV.

\section{Discussion}

Our subjects, both boys and girls, had slightly taller stature than average. In girls, there was no difference between our subjects and the Japanese standard when the PGS started. In boys, the PGS of our subjects started about 6 months earlier than the Japanese standard.

In this study there was no significant cor-

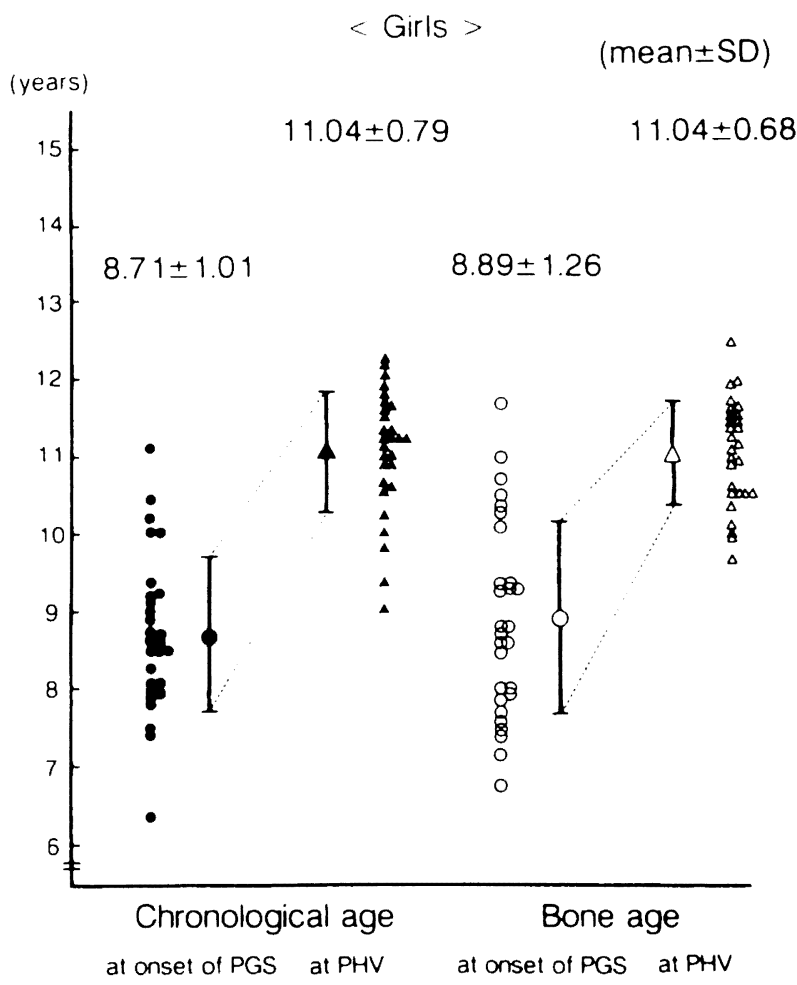

\section{3-b}

Fig. 3 Differences between changes in chronological age and bone age at the onset of PGS and at PHV in boys (3-a) and girls (3-b). 
relation between the bone age at the onset of PGS and the final height in normal children. Burns et al. (5) and Bourguignon et al. (6) also report that the differences in bone age at the onset of puberty did not significantly affect the final height in boys with hypopituitarism treated with $\mathrm{GH}$ who entered puberty at a later age than normal children. A significant negative correlation between the rate of bone maturation during puberty and the bone age at the onset of PGS is in agreement with the report by Bourguignon et al. (6). This suggests that bones

Height velocity for chronological age (Boys)

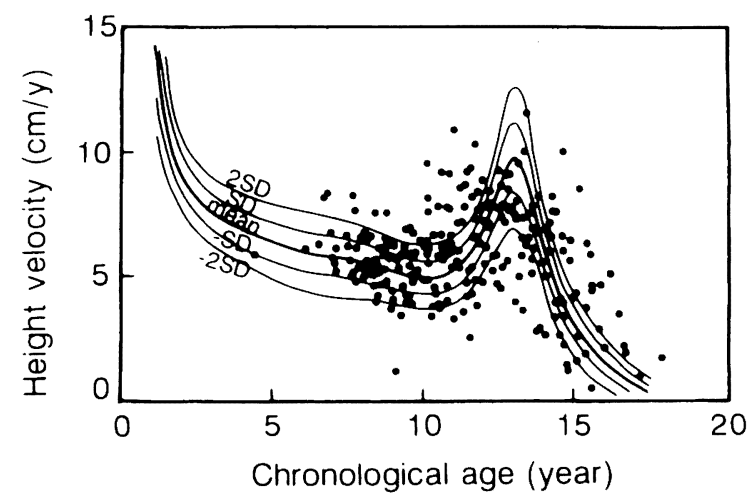

4-a

Height velocity for chronological age (Girls)

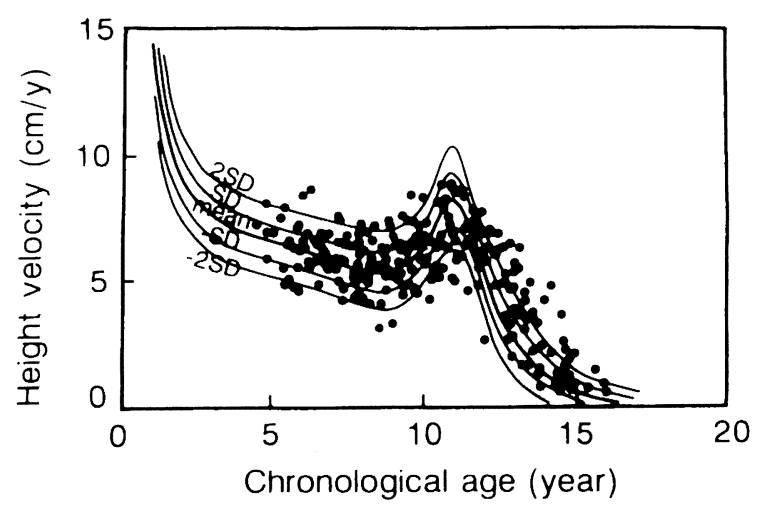

4-b mature earlier when they are exposed to sex steroids earlier.

Bone ages at PHV were concentrated around 13 years in boys and 11 years in girls; these ages were equivalent to the ages at PHV on standard growth velocity curves for Japanese children (4). Sizonenko et al. (7) report a longitudinal study which showed no differences in bone age at PHV among normal children with advanced puberty, normal puberty, and delayed puberty. Satoh et al. (8) also report the same result in boys with non-endocrine short stature.

Height velocity for bone age (Boys)

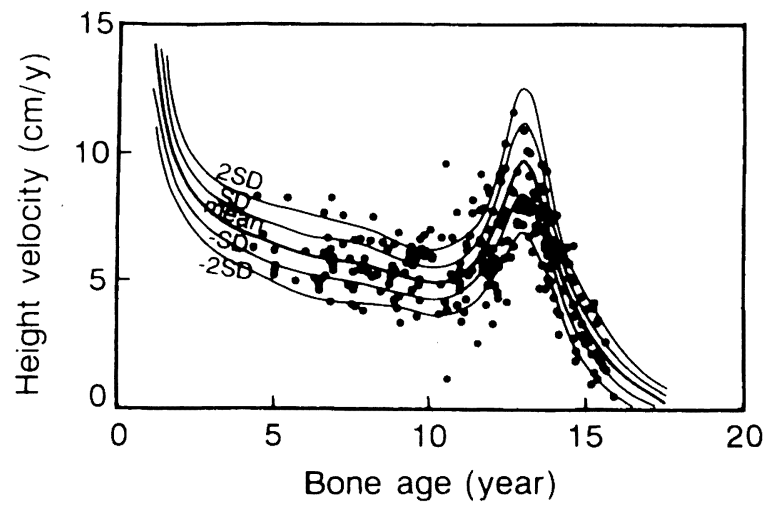

4-c Height velocity for bone age (Girls)

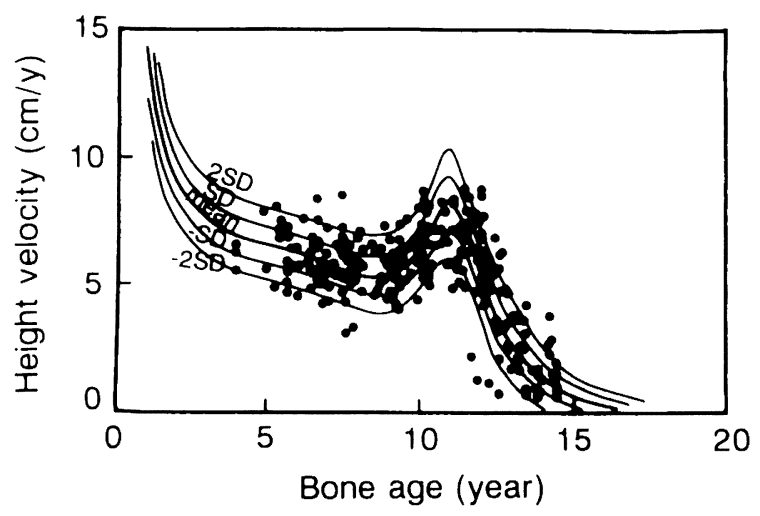

4-d

Fig. 4 Height velocity for chronological age and bone age in boys (4-a, c) and girls (4-b, d). 


\section{BA and Growth during Puberty}

This suggests that bone growth potential depends on bone age.

Although boys and girls who entered puberty at a young bone age were short at the onset of PGS, the large pubertal height gain due to greater growth potential of young bones, made their final heights reach the standard level.

Table 3 Correlation coefficients between $\Delta$ HSDS and various factors.

Boys Girls

$\begin{array}{lll}\text { At onset of PGS } & & \\ \text { CA } & 0.559 * * & 0.301 \\ \text { BA } & 0.329 & 0.022 \\ \text { CA-BA } & 0.056 & 0.345 \\ \text { Height SDS for CA } & -0.350 & 0.182 \\ \text { Height SDS for BA } & -0.254 & 0.424 *\end{array}$

At PHV

$\begin{array}{lll}\text { CA } & 0.708 * * & 0.460 * \\ \text { BA } & 0.209 & -0.168 \\ \text { CA-BA } & 0.704 * * & 0.639 * * \\ \text { Height SDS for CA } & -0.477 * * & 0.184 \\ \text { Height SDS for BA } & 0.144 & 0.677 * *\end{array}$

Pubertal height gain $-0.008 \quad 0.338$

$* \quad: \mathrm{p}<0.05 \quad * *: \mathrm{p}<0.01$

CA : Chronological age

BA : Bone age

$\triangle H S D S:$ difference between final height SDS and height SDS at 7 years old
Tanaka et al. report that the later pubertal maturation occurs, the taller the final height achieved when the height before puberty is of the same level (1). Our results confirm this, because $\Delta$ HSDS correlated to chronological age at PHV both in boys and girls.

\section{Conclusions}

1) The variation in bone age at the onset of PGS has no influence on final height in children with normal puberty. 2) The rate of bone maturation during puberty is proportional to bone age. 3) Bone growth potential depends on bone age. 4) The later puberty starts, the larger the increase in the height SD score for chronological age after the pubertal period.

\section{Acknowledgements}

We would like to acknowledge Dr. K Satoh, School of Dentistry. Tohoku University, Prof. M Murata, Tokyo Women's Medical College Daini Hospital, Prof. N Matsuo, Keio University, Prof. K Ashizawa, Otsuma Women's University, and Prof. F Ohtsuki, Tokyo Metropolitan University for their fruitful suggestions.

\section{References}

1. Tanaka T, Suwa S, Yokoya S, Hibi I. Analysis of linear growth during puberty: Influence of the time of pubertal growth spurt on the final height. J Jpn Pediatr Soc 1988; 92: 2419-24. (In Japanese)

2. Tanaka T, Suwa S, Yokoya S, Hibi I, Watanabe T. Prediction of final height at onset of pubertal growth spurt. J Jpn Pediatr Soc 1990; 94: 1586-91. (In Japanese) 
3. Murata M, Matsuo N, Tanaka T, Ohtsuki F, Ashizawa $\mathrm{K}$, Tatara $\mathrm{H}$, et al. Nihonjin hyoujun kotsu seijuku atlas (Standard bone growth atlas for Japanese). Tokyo, Kanehara Shuppan 1993; (in Japanese)

4. Suwa S, Tachibana K, Maesaka H, Tanaka T, Yokoya S. Longitudinal standards for height and height velocity for Japanese children from birth to maturity. Clin Pediatr Endocrinol 1992; 1: 5-13.

5. Burns EC, Tanner JM, Preece MA, Cameron N. Final height and pubertal development in 55 children with idiopathic growth hormone deficiency, treated for between 2 and 15 years with human growth hormone. Eur J
Pediatr 1981; 137: 155-64.

6. Bourguignon JP, Vandeweghe $M$, Vanderschueren-Lodeweyckx M, Malvaux P, Wolter R, Du Caju M, et al. Pubertal growth and final height in hypopituitary boys: a minor role of bone age at onset of puberty. $\mathrm{J}$ Clin Endocrinol Metab 1986; 63: 376-82.

7. Sizonenko PC, Limoni C. Height velocity during puberty in relation to bone age. Pediatr Res Suppl 1993; 33: 89.

8. Satoh M, Tanaka T, Tanae A, Hibi I. Height velocity for bone age in male children with non-endocrine short stature. Clin Pediatr Endocrinol Suppl 1994; 4 (3): 121-4. 